\title{
EXPERIMENTAL STUDY ON THE SEISMIC BEHAVIOUR OF RC BEAMS WITH STANDING AND HANGING WALLS
}

\author{
Koichi Kusunoki ${ }^{1}$, Chikashi Nishikura ${ }^{2}$ and Akira Tasai ${ }^{3}$
}

(Submitted February 2017; Reviewed May 2017; Accepted June 2017)

\begin{abstract}
Recently, earthquake damage to non-structural walls has become one of the important issues in Japan. Some buildings were demolished after the 2011 Tohoku Earthquake due to damage of non-structural walls without any significant damage in structural members. After that, several projects were launched to develop a new method to take into account the effect of non-structural walls (hanging, standing, and wing walls). In this paper, experimental test results for beam-column joints with non-structural walls are presented. The objectives of the tests were to investigate the equivalent length and hinge location of beams with hanging and standing walls. The results showed that the yield hinge located at the surface of the wing walls and beamcolumn joint should be modelled as rigid to estimate the deformation of the beams, regardless of the thickness and height of the wall. A tri-linear modelling method for beams with hanging and standing walls was also proposed, and its applicability was confirmed with the test results.
\end{abstract}

\section{INTRODUCTION}

Non-structural walls in reinforced concrete (referred to as RC, hereafter) structures are also made of RC in Japan as shown in Figure 1. Although structural and non-structural walls are both $\mathrm{RC}$, the structural wall needs to satisfy the requirements of the Building Standard Law of Japan [1] (referred to as BSL, hereafter) and the non-structural wall does not. The requirements of BSL, Article 78-2 for RC structural walls [2] are:

- Thickness shall be $120 \mathrm{~mm}$ or more.

- Steel bars with a diameter of $12 \mathrm{~mm}$ or more shall be arranged around the openings of bearing walls.

- Bearing walls shall be provided with horizontal and vertical reinforcing bars with a diameter of $9 \mathrm{~mm}$ or more at an interval of $300 \mathrm{~mm}$ or less.

- Joints with surrounding columns and beams shall be constructed so that the existing stress at the parts concerned may be transferred.

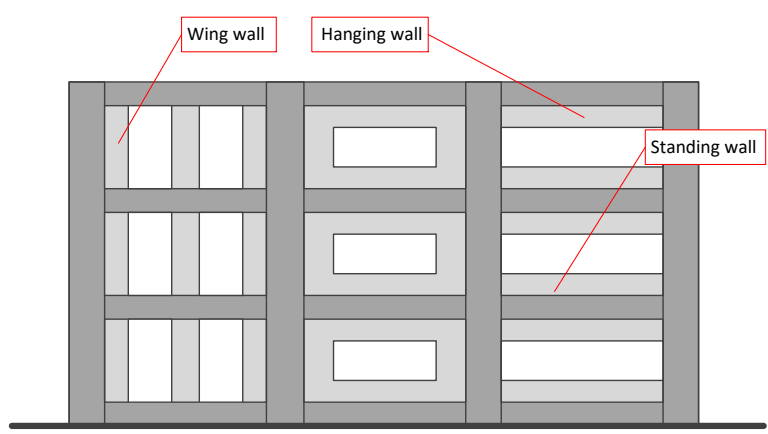

Figure 1: Building with non-structural walls (wing wall, hanging wall, and standing wall).

If the wall does not agree with these requirements from Article $78-2$, it is considered a "non-structural wall". Usually some non-structural walls are arranged according to architectural requirements such as holes for ventilators and air-conditioners.
The effect of the non-structural walls on the lateral strength used to be neglected during analysis, where their weights are considered but their strengths are ignored. However, nonstructural walls were often severely damaged during earthquakes. Figure 2 shows the damage of a column with hanging and standing walls during the 2011 Tohoku Earthquake [3]. The hanging walls were also severely damaged and the column failed in shear with shorter clear height than that considered during analysis. There were apartment buildings that were demolished after the 2011 Tohoku earthquake exclusively due to damage of non-structural walls.

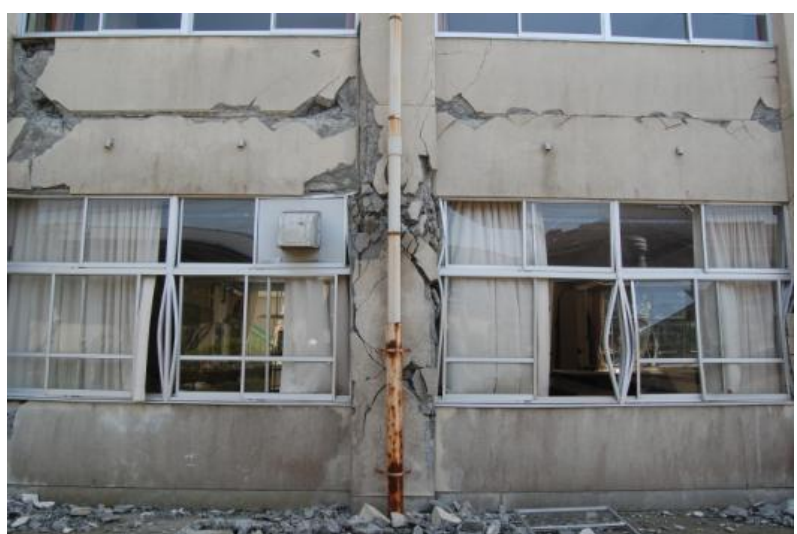

Figure 2: Damage due to non-structural walls during the 2011 Tohoku Earthquake.

One reason why the effect of the non-structural walls used to be ignored, i.e., why walls are designed as non-structural walls, is that there is no method proposed to evaluate the behaviour of the members with these walls. Because of that, standing and hanging walls were considered to contribute to beam strength when computing the design shear force in the joint, but the wing walls were ignored when computing flexural strength and the capacity of the joint.

\footnotetext{
1 Associate Professor, Earthquake Research Institute, the University of Tokyo, kusunoki@eri.u-tokyo.ac.jp

2 Structural Engineer, Mitsubishi Jisho Sekkei, chikashi.nishikura@mj-sekkei.com

3 Professor, Yokohama National University, tasai@ynu.ac.jp
} 
Several research projects have been launched under the support of Japan Science and Technology Agency (JST) and Ministry of Land, Infrastructure and Transport and Tourism (MLIT) to propose a method to consider the effect of non-structural walls. The effect of walls to flexural and shear capacities were tested before [4], [5]. One of the key issues, which is not well investigated, is the prediction of the location of the yield hinge and the length of the rigid zone in the beam-column joint (Figure 3). When a beam does not have standing and hanging walls, the end of the horizontal rigid zone is assumed to be at $\mathrm{D} / 4$ inside of the face of the column, where $\mathrm{D}$ is the depth of the beam. For beams and columns with wing, standing, and hanging walls, the same assumption is applied to define the rigid length in practice, as shown in Figure 3.

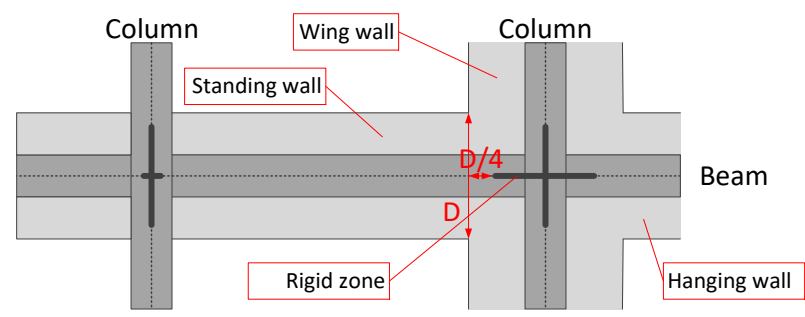

Figure 3: Rigid length at the beam-column joint.

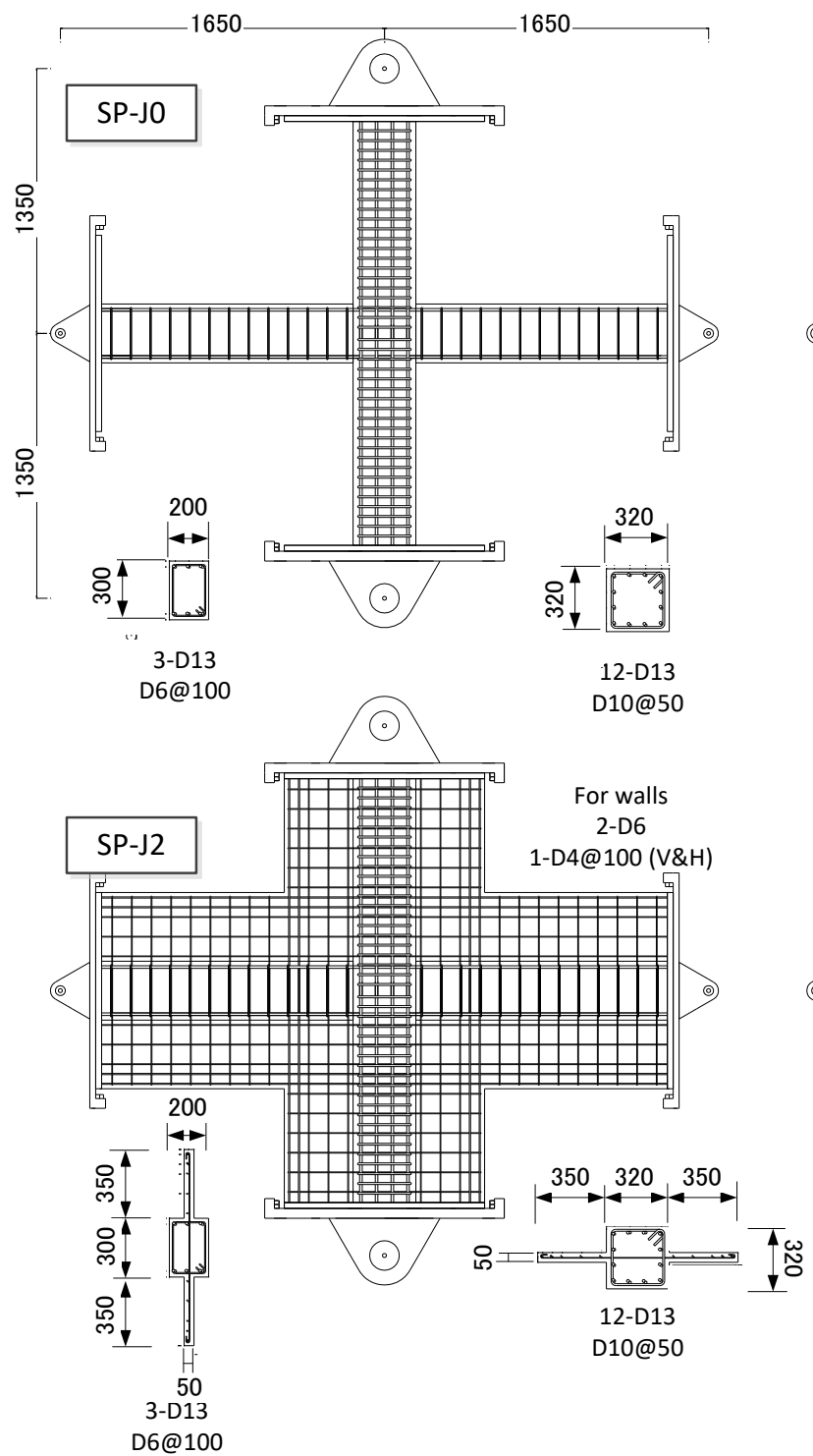

In order to investigate an appropriate rigid length to estimate the deformation of the beam and the location of the yield hinge in the beam, static loading tests were conducted on four beamcolumn joint specimens with wing, standing and hanging walls.

\section{OUTLINE OF THE SPECIMENS}

The dimensions and bar arrangements of the specimens are shown in Figure 4, and their properties are listed in Table 1. The prototype structure is 7-storey R.C building with span length of $7.92 \mathrm{~m}$ and storey-height of $6.48 \mathrm{~m}$, which is shown as design example in the AIJ standard [6]. The tested beam-column joint locates at the second floor. The scale of the specimens was about 5/12. The beam with hanging and standing walls of SP$\mathrm{J} 1$ is the same as the specimen that was loaded under the antisymmetric moment distribution prior to this test [7]. SP-J0 is the specimen without walls. SP-J2 has thinner walls of $50 \mathrm{~mm}$ than SP-J1 to investigate the effect of the wall thickness. SP-J3 has shorter wall length of $200 \mathrm{~mm}$ than SP-J1 to investigate the effect of the wall height.

As mentioned earlier, the standing and hanging walls were taken into account for beam strength when computing the design shear force in the joint, but the wing walls were ignored when computing the flexural strength and the capacity of the joint. By following the structural design practice, the specimens were designed so that the flexural strength ratio of column to

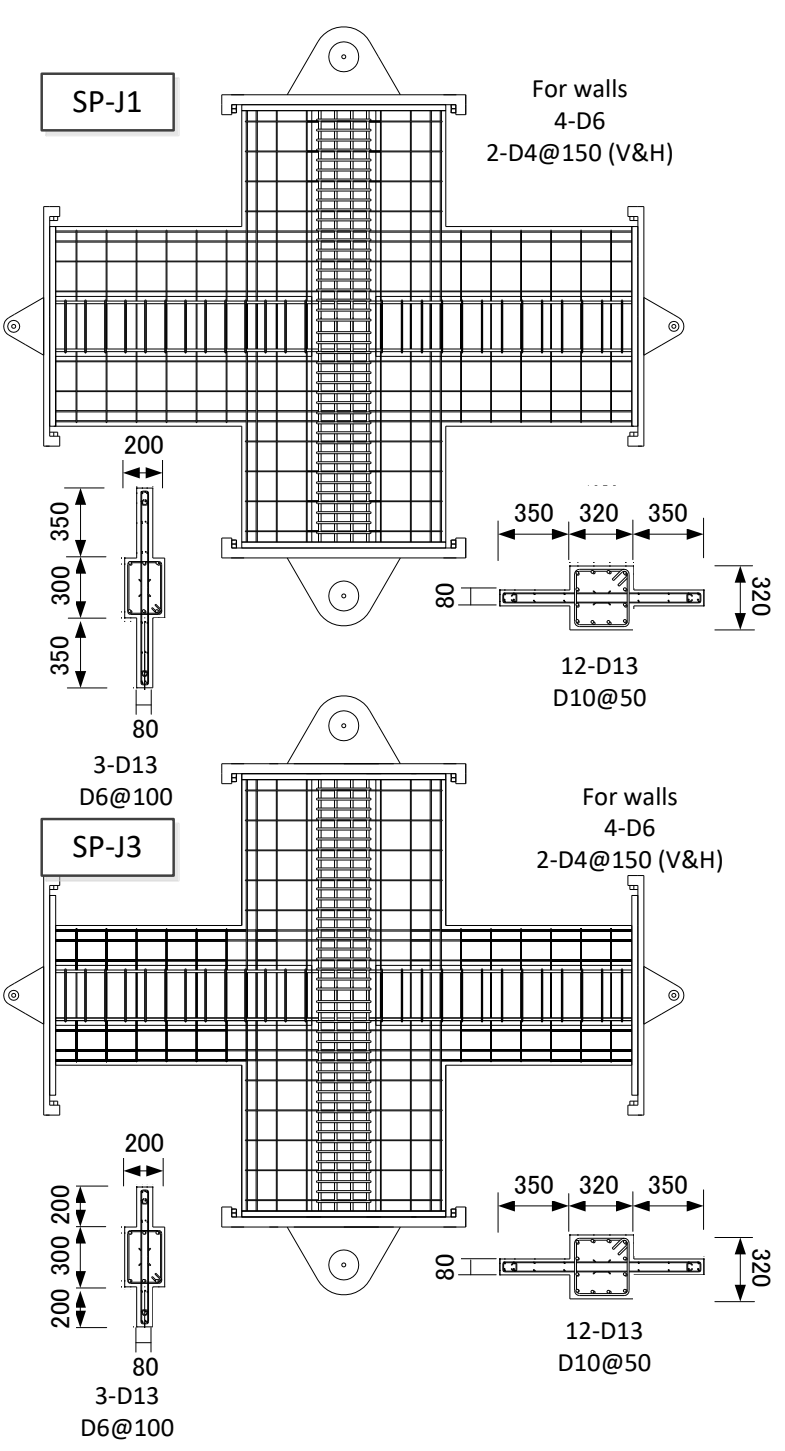

Figure 4: Drawings of test specimens. 
beam with standing and hanging walls becomes about 1.0. The flexural strength ratios of column with wing walls to the beam with standing and hanging walls were more than 3.0 as shown in Table $\mathbf{1}$.

\section{LOADING AND MEASUREMENT}

The loading setup is shown in Figure 5. Two vertical hydraulic oil jacks were used to keep the loading beam parallel to the ground and apply the axial force of $614.4 \mathrm{kN}$ (axial force ratio of $0.2 \cdot \mathrm{A}_{g} \cdot f_{c}$ ). Two vertical rods with load cells were connected at the end of the beam with pin connections to support the beam and to measure the shear force acting in the beam. Lateral hydraulic jacks were used to apply lateral force to the specimen.

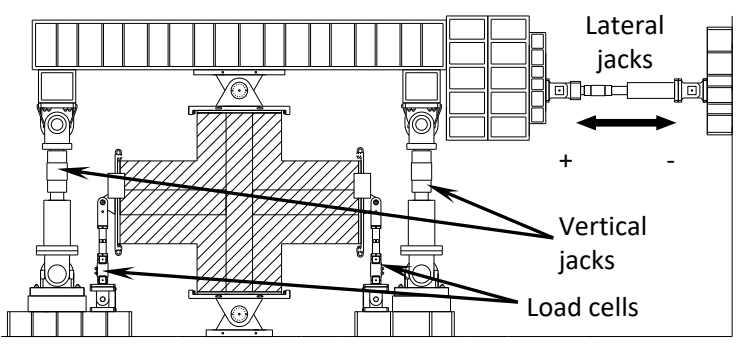

Figure 5: Loading system.

The applied loading history is shown in Figure 6. At first, the specimen was loaded to $50 \%$ of the cracking strength $\left(\mathrm{Q}_{\mathrm{cr}}\right)$, and $100 \%$ of $\mathrm{Q}_{\mathrm{cr}}$ for one cycle each under force control. After these two cycles, the loading was controlled by displacement, and the specimen was loaded with the peak deflection angles, $\mathrm{R}$, of $\pm 1 / 1200( \pm 0.083 \%), \pm 1 / 800( \pm 0.125 \%), \pm 1 / 400 \quad( \pm 0.25 \%)$, $\pm 1 / 200( \pm 0.5 \%)$, and $\pm 1 / 100( \pm 1 \%)$ for two cycles each. Finally, one cycle with $\mathrm{R}$ of $\pm 1 / 25( \pm 4 \%)$ was applied.

The storey deformation, deflection angles and axial deformations of beams and columns, and shear deformation at beam-column joints were measured with the attached transducers. Strains of main bars and shear reinforcements of beams and columns, and reinforcement in the walls were measured with the attached strain gauges. The lateral force was measured with the load cells attached to the lateral hydraulic jacks, and the shear forces in the beams were measured with the load cells attached to the steel rods.

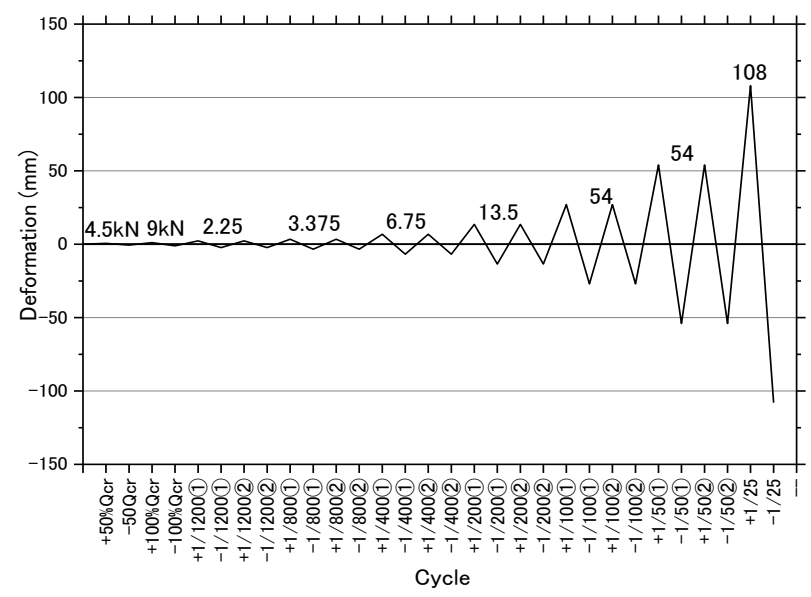

Figure 6: Loading history.

Table 1: Properties of the specimens.

\begin{tabular}{|c|c|c|c|c|}
\hline & SP-J0 & SP-J1 & SP-J2 & SP-J3 \\
\hline Beam tensile bars & \multicolumn{4}{|c|}{ 3-D13 $\left(\sigma_{y}=365 \mathrm{MPa}\right)$} \\
\hline Beam tensile bar ratio, $p_{t}$ & \multicolumn{4}{|c|}{$0.63 \%$} \\
\hline Beam shear reinforcement & \multicolumn{4}{|c|}{ 2-D6@100 ( $\left.\sigma_{\mathrm{y}}=359 \mathrm{MPa}\right)$} \\
\hline Beam shear reinforcement ratio & \multicolumn{4}{|c|}{$0.32 \%$} \\
\hline Column main bars & \multicolumn{4}{|c|}{$12-\mathrm{D} 13\left(\sigma_{y}=365 \mathrm{MPa}\right)$} \\
\hline Column main bar ratio, $p_{g}$ & \multicolumn{4}{|c|}{$1.48 \%$} \\
\hline Column shear reinforcement & \multicolumn{4}{|c|}{ 2-D10@50 $\left(\sigma_{\mathrm{y}}=359 \mathrm{MPa}\right)$} \\
\hline Column shear reinforcement ratio & \multicolumn{4}{|c|}{$0.89 \%$} \\
\hline Wall thickness (mm) & \multirow{5}{*}{-} & 80 & 50 & 80 \\
\hline Standing/Hanging wall height $(\mathrm{mm})$ & & \multicolumn{2}{|c|}{350} & 200 \\
\hline Wall reinforcement & & $\begin{array}{c}2-\mathrm{D} 4 @ 150 \\
\left(\sigma_{\mathrm{y}}=295 \mathrm{MPa}\right)\end{array}$ & $\begin{array}{c}1-\mathrm{D} 4 @ 150 \\
\left(\sigma_{\mathrm{y}}=295 \mathrm{MPa}\right)\end{array}$ & $\begin{array}{c}2-\mathrm{D} 4 @ 150 \\
\left(\sigma_{\mathrm{y}}=295 \mathrm{MPa}\right)\end{array}$ \\
\hline Lateral reinforcement ratio & & $0.23 \%$ & $0.28 \%$ & $0.23 \%$ \\
\hline Flexural reinforcement & & $\begin{array}{c}\text { 4-D6 } \\
(\sigma y=345 \mathrm{MPa})\end{array}$ & $\begin{array}{c}2-\mathrm{D} 6 \\
(\sigma \mathrm{y}=345 \mathrm{MPa})\end{array}$ & $\begin{array}{c}\text { 4-D6 } \\
(\sigma y=345 \mathrm{MPa})\end{array}$ \\
\hline $\begin{array}{l}\text { Measured concrete compressive strength, } \\
\sigma_{B}\left(\mathrm{~N} / \mathrm{mm}^{2}\right)\end{array}$ & 35.6 & 34.8 & 32.2 & 34.8 \\
\hline Column/Beam flexural strength ratio* & 3.89 & 3.04 & 3.65 & 3.80 \\
\hline
\end{tabular}

\footnotetext{
*: wing walls, standing walls, and hanging walls were taken into account.
} 


\section{TEST RESULTS}

The storey shear versus storey drift of the specimens are shown in Figure 7. Since the shear span of SP-J0 is longer than the other specimens, the storey shear of SP-J0 with the same shear span as the other specimens is also shown as dashed lines in Figure 7, assuming that the yield hinge location was at the surface of the wing wall. As shown in Figure 7 (a), beam without standing and hanging walls showed high ductility and restoring force did not degraded. On the contrary, the restoring force of the beams with walls dropped down due to the compression failure of the wall. when it reached the maximum. However, residual restoring forces were higher than that of the beams without walls and the behavior was stable and ductile. The crack patterns of the specimens after the completion of testing and photos taken at $+1 / 25(4 \%)$ deflection angle are shown in Figure 8 and Figure 9, respectively. Cracking damage in beam-column joints was not evident for any specimens. The damage concentrated on the surface of the wing walls. The restoring forces of SP-J1, SP-J2 and SP-J3, which had nonstructural walls, dropped after reaching the peak due to crushing of concrete at the surface of the wing walls. SP-J2, which had shorter standing and hanging walls, showed smaller deterioration compared to SP-J1 and SP-J3.

The residual storey shears of SP-J1, SP-J2 and SP-J3 were, however, greater than that of SP-J0 (modified with the same shear span) up to a storey drift angle of $1 / 25(4 \%)$.

\section{DISCUSSION}

\section{Rigid Length}

In order to measure the flexural deformation of the beam, a transducer was attached as shown in Figure 10, to measure $\delta_{1}$ for the beam length of $\ell(=810 \mathrm{~mm})$. From the relationship between measured shear force in the beam, $Q_{b}$, and $\delta_{1}$ in elastic cycles (first two cycles with $50 \%$ and $100 \%$ of $\mathrm{Q}_{\text {cr }}$ ), the initial stiffness of the beam, $K_{1}$, was calculated as the slope of the relationship using the least squares method. The elastic flexural stiffness of the beam, $E I$, was calculated as:

$\mathrm{EI}=\frac{K_{1} \cdot \ell^{3}}{3}$

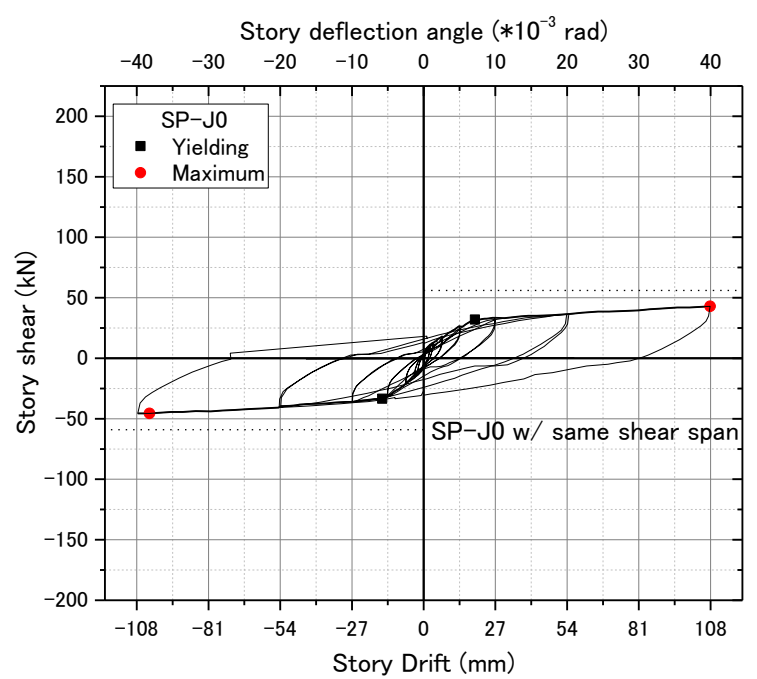

(a) SP-J0

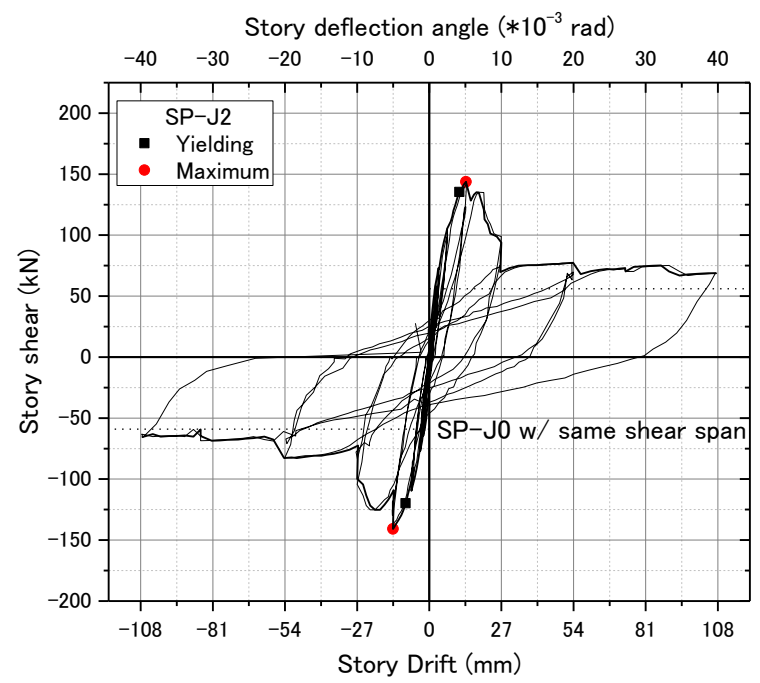

(c) $S P-J 2$

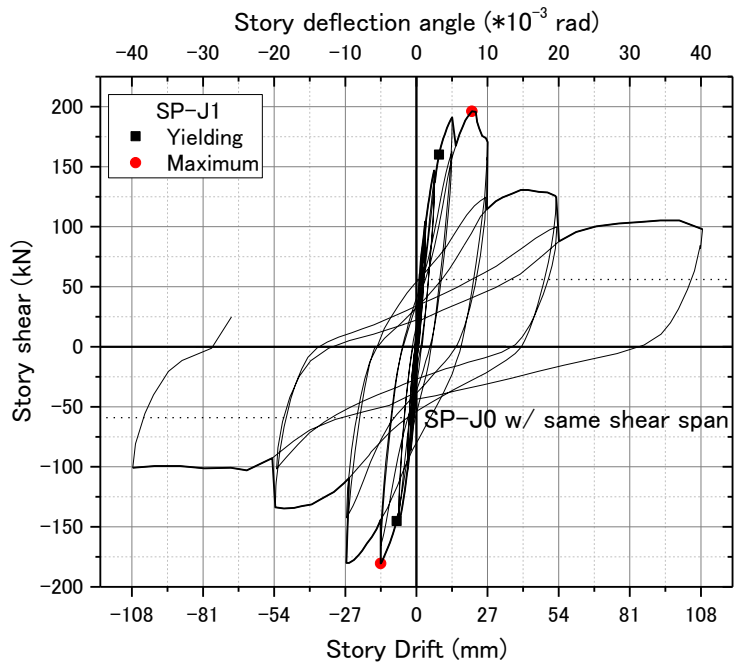

(b)SP-J1

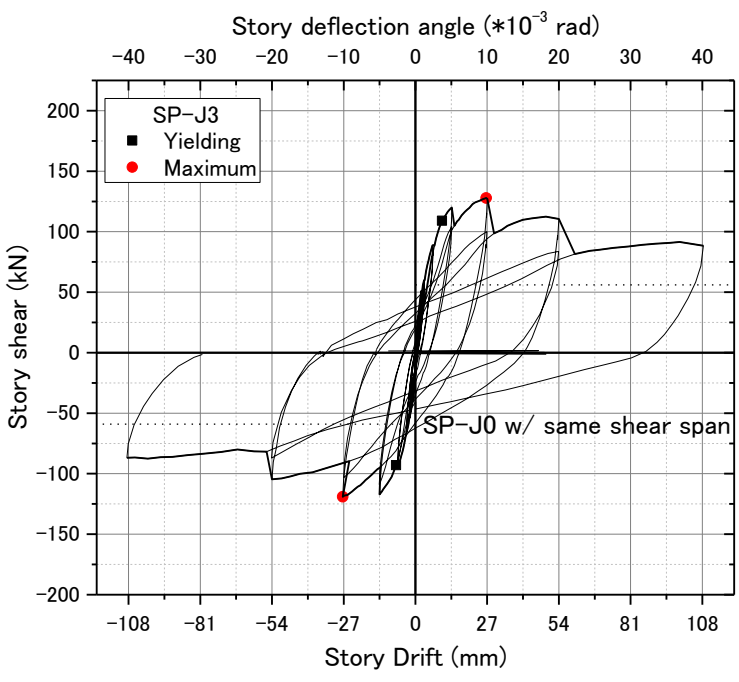

(c)SP-J3

Figure 7: Measured relationship of storey-shear versus storey drift. 

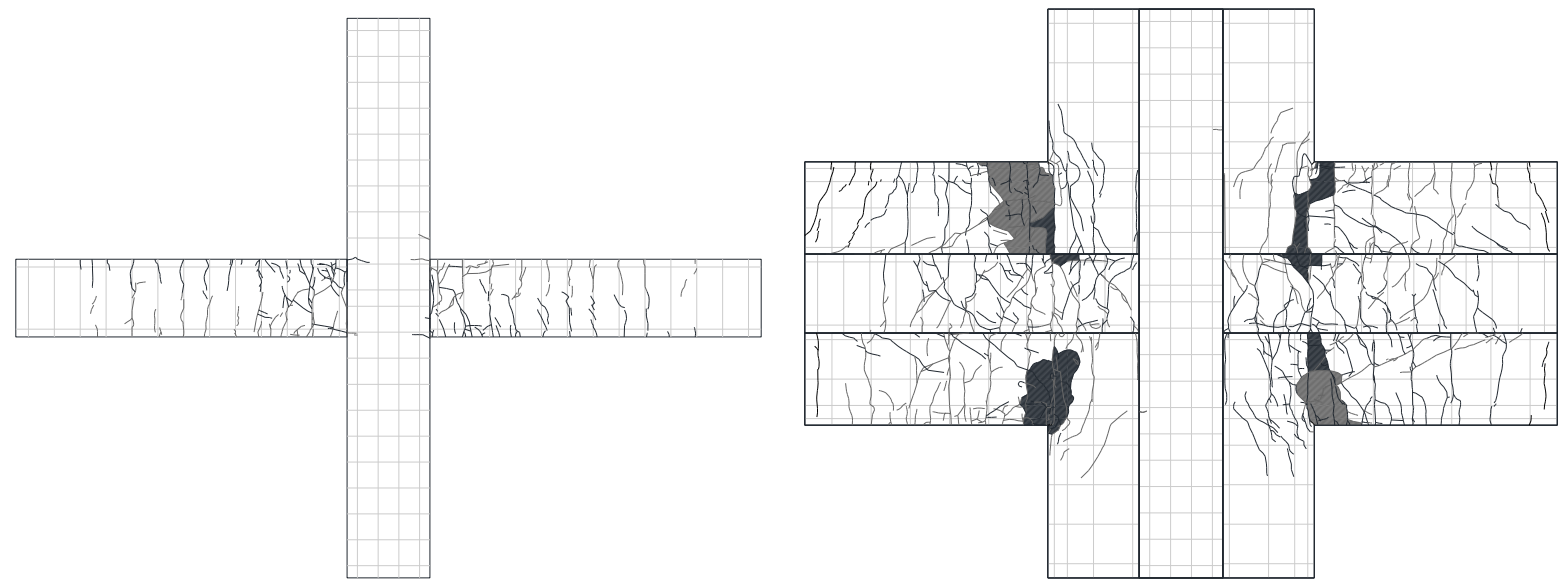

(a) $S P-J 0$

(b)SP-J1

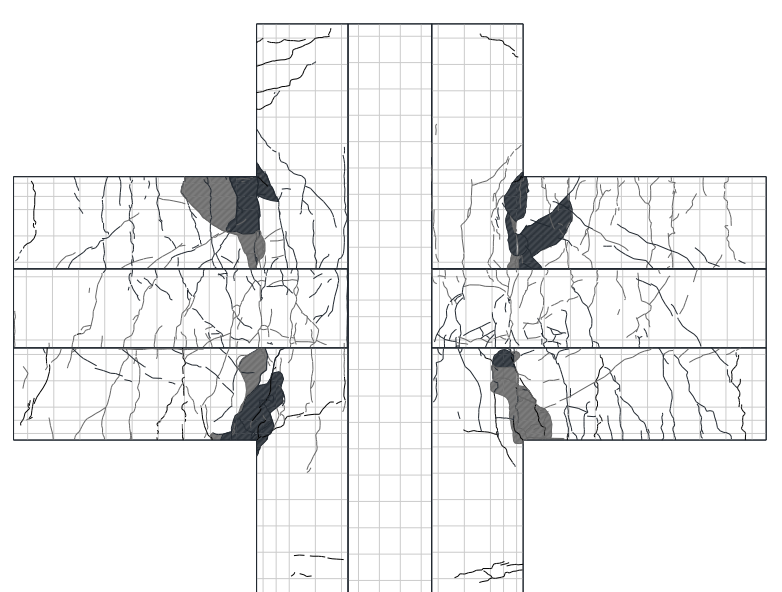

(c) $S P-J 2$

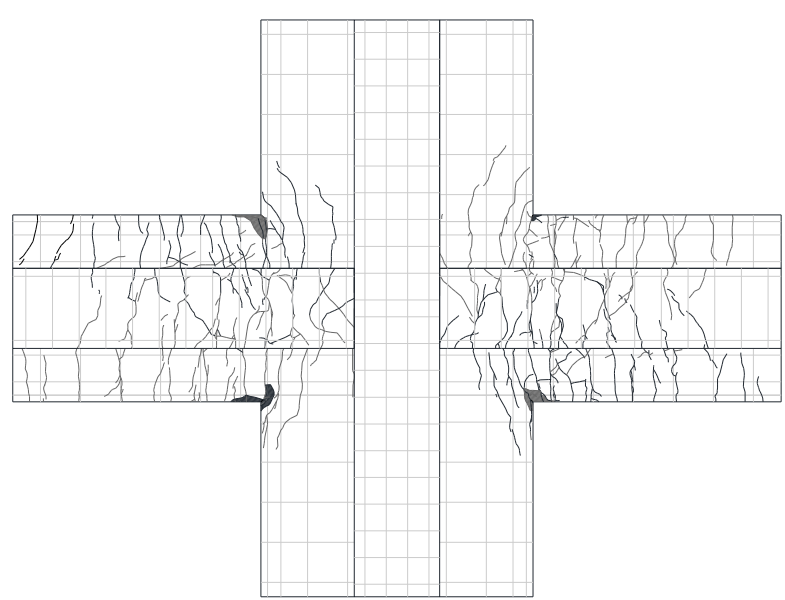

(c)SP-J3

Figure 8: Cracking patterns after the loading.

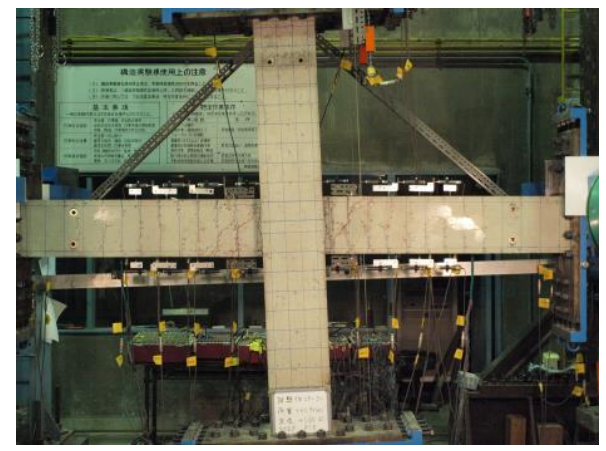

(a) $S P$-JO

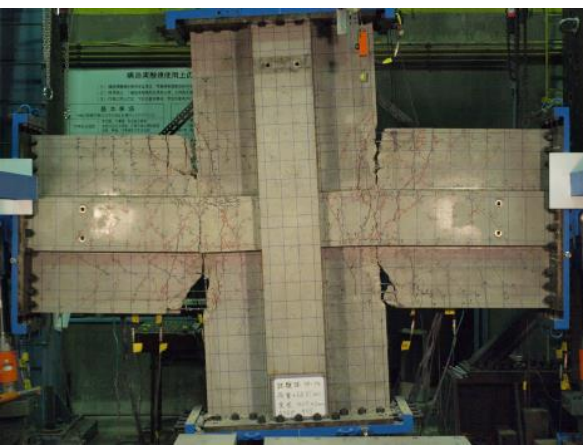

(c) $S P-J 2$

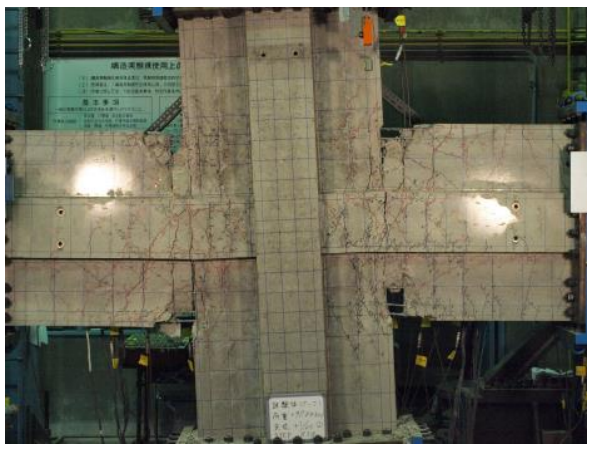

(b)SP-J1

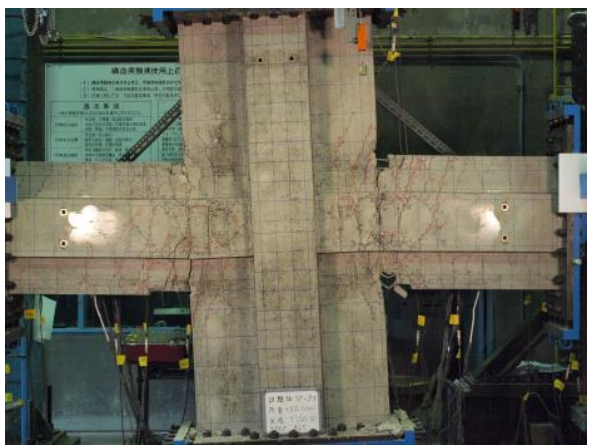

(c) SP-J3

Figure 9: Damage condition at the $+1 / 25(0.04 \mathrm{rad})$ deflection angle. 


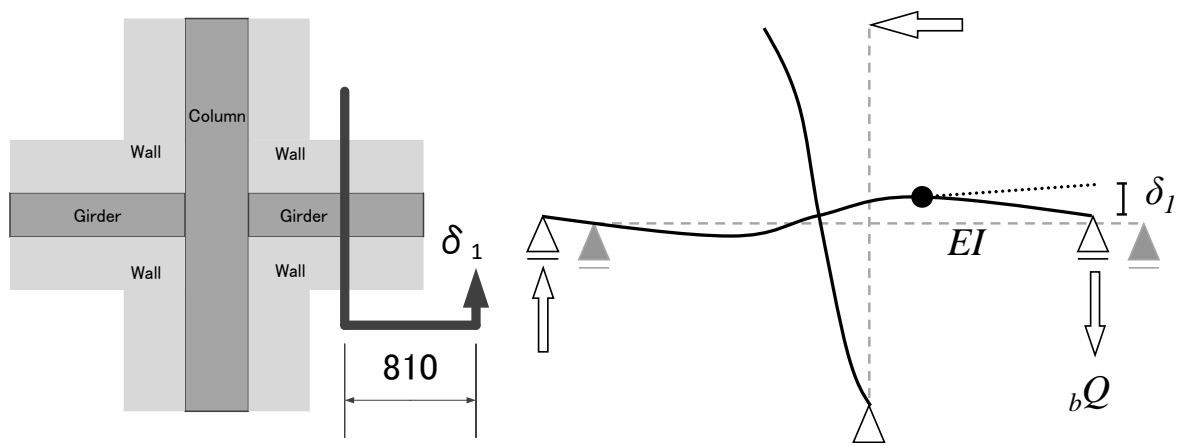

Figure 10: Flexural stiffness of the beam.

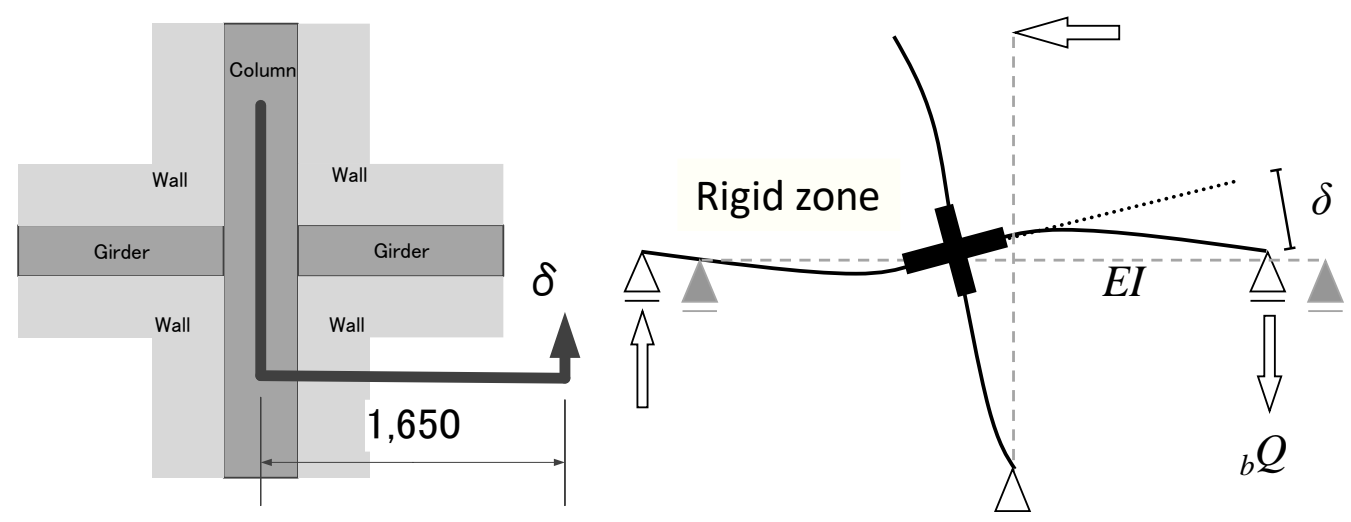

Figure 11: Measuring system for rigid length in the beam-column joint.
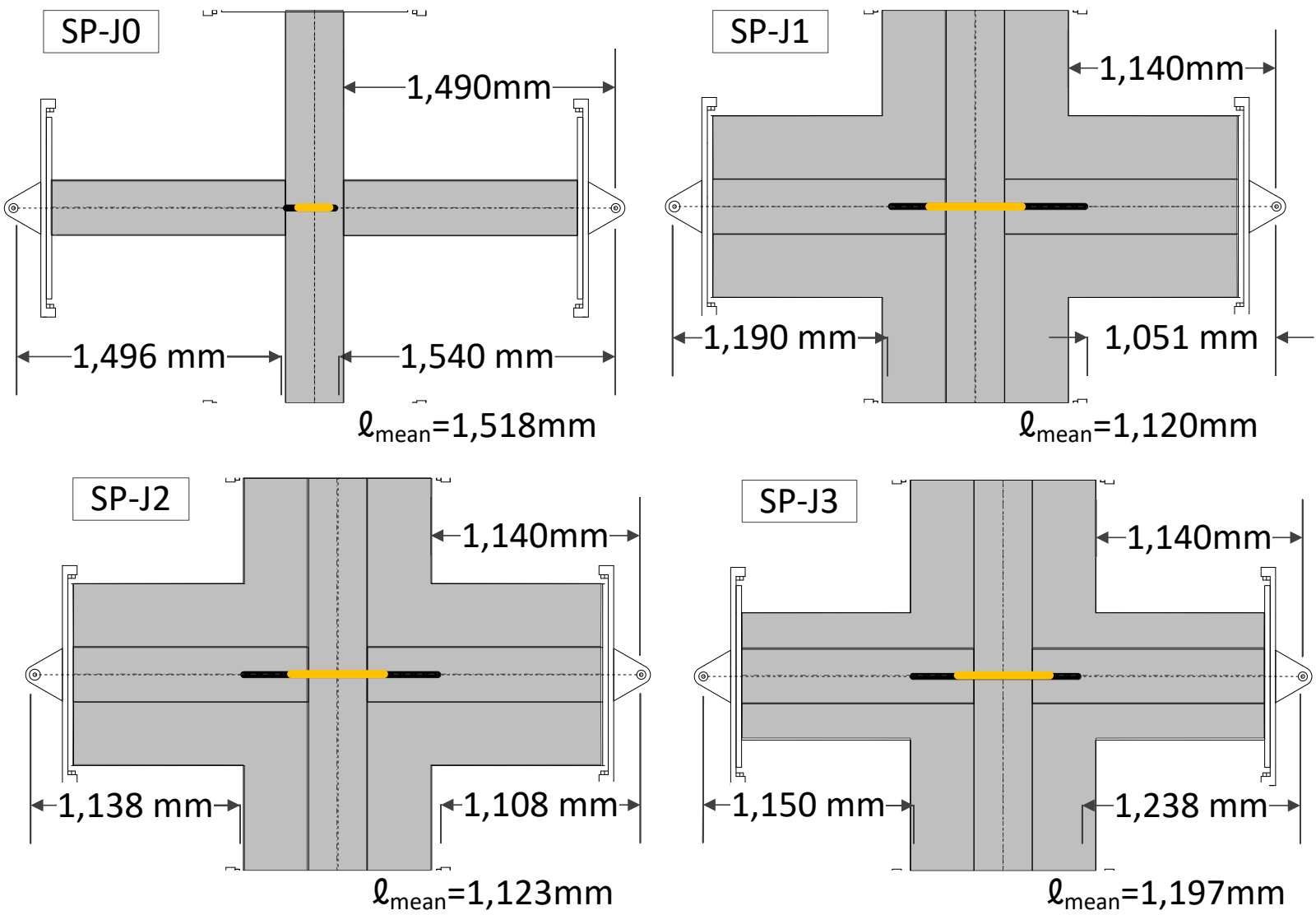

Figure 12: Rigid length of the specimens (Black: test results, Orange: conventional assumption). 
Another transducer was also attached as shown in Figure 11 to measure the flexural deformation of the beam from the centre of the beam-column joint, $\delta$ with the length of $1,650 \mathrm{~mm}$. From the relationship between measured shear force in the beam, $Q_{b}$, and $\delta$ in elastic cycles (first two cycles with $50 \%$ and $100 \%$ of $\mathrm{Q}_{\mathrm{cr}}$ ), the initial stiffness of the whole beam (from the center of the joint), $K_{0}$, was calculated as the slope of the relationship using the least squares method. Then the effective length of the beam, $\ell^{\prime}$ was calculated as :

$\ell^{\prime}=\sqrt[3]{\frac{3 E I}{K_{0}}}$

The calculated rigid length to evaluate the deformation of the beam is shown in Figure 12. The calculated length is much longer than the conventional assumption, which is D/4 inside the face of the wing wall ( $D$ is the total height of the beam including the height of the walls). There was no significant difference among SP-J1 to SP-J3. This means that the thickness and height of the wall were not effecting the rigid length, perhaps because the flexural strength of the column with wing walls was much higher than that of the beam. The flexural strength ratio may be decreased when a rational way to evaluate the behaviour of columns and beams with walls is proposed. At

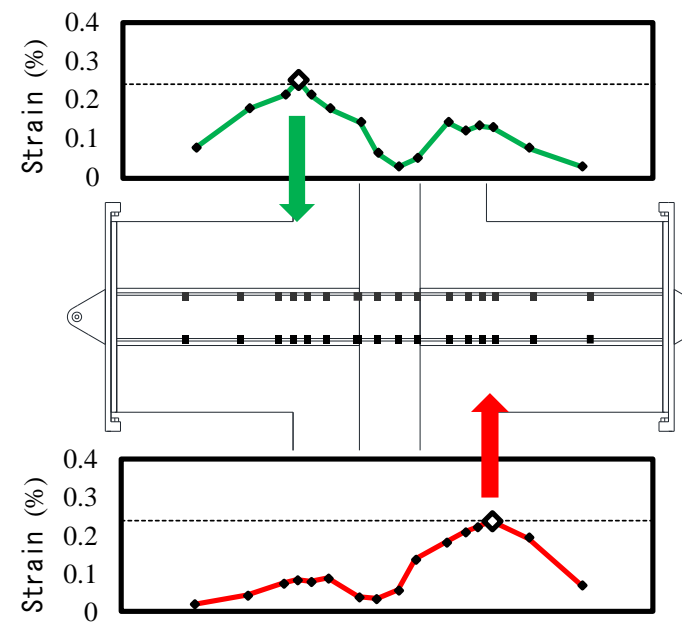

(a) $S P-J 1$ that time, the rigid length is predicted to become shorter than this result, and further experimental tests are required.

\section{Yield Hinge Location}

The locations of the strain gauges on the main bar of the beams and the measured strain when the maximum strain just exceeds the yield strain obtained from material tests are both shown in Figure 13. The first yielding occurred at the surface of the wing walls or $75 \mathrm{~mm}$ toward the beam from the surface. No significant difference was observed among SP-J1, SP-J2, and SP-J3.

The storey shear at first yielding measured during the experimental test and calculated with section analysis (fibre analysis) are compared in Figure 14. The yield hinge locations of the beams were assumed at the surface of the wing walls according to the earlier discussion. The moment carried by each column at the node was assumed to be the same. It can be seen from the figure that the calculated storey shears coincide very well with test results. The ratio of the averaged storey shear of the experimental test to the calculation is $0.95 \%$ to $1.02 \%$, which shows good agreement. It means that the assumption of the rigid length is confirmed.

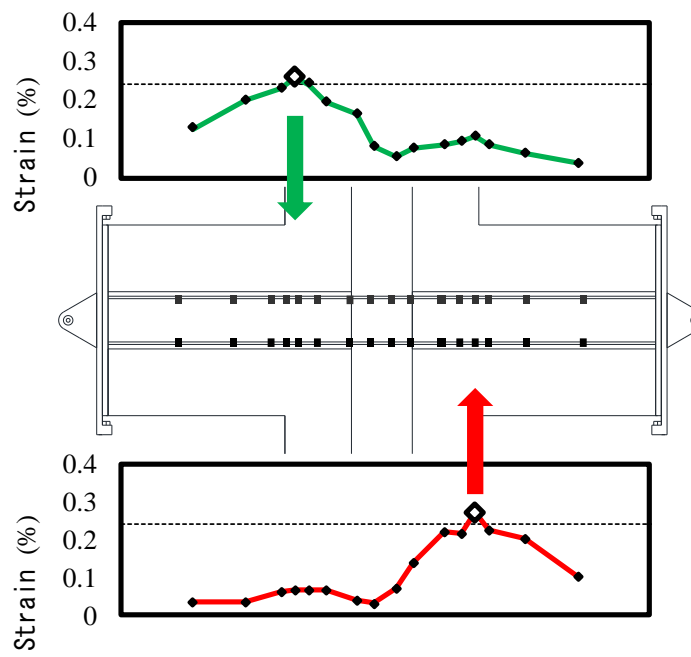

(b) $S P-J 2$

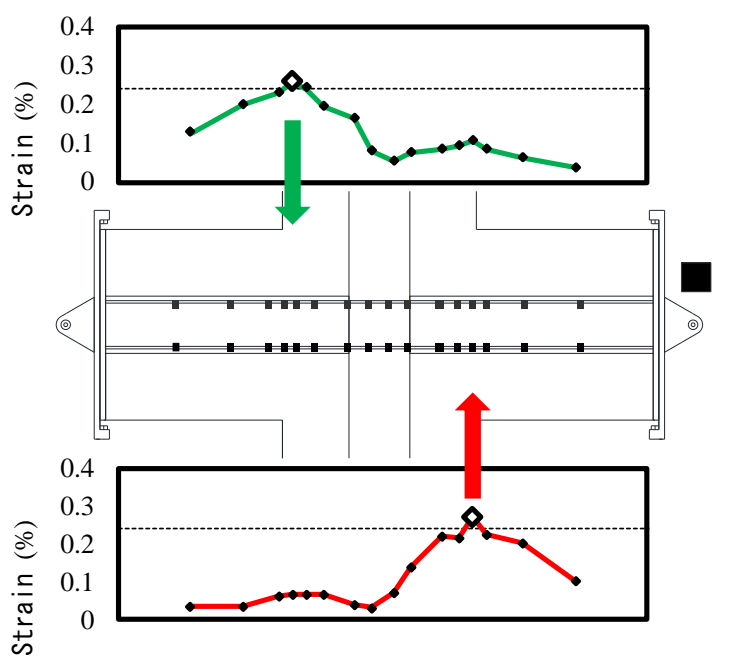

Location of the strain gauges

(c) $S P-J 3$

Figure 13: Location of the yielding shown by strain gauge measurements. 


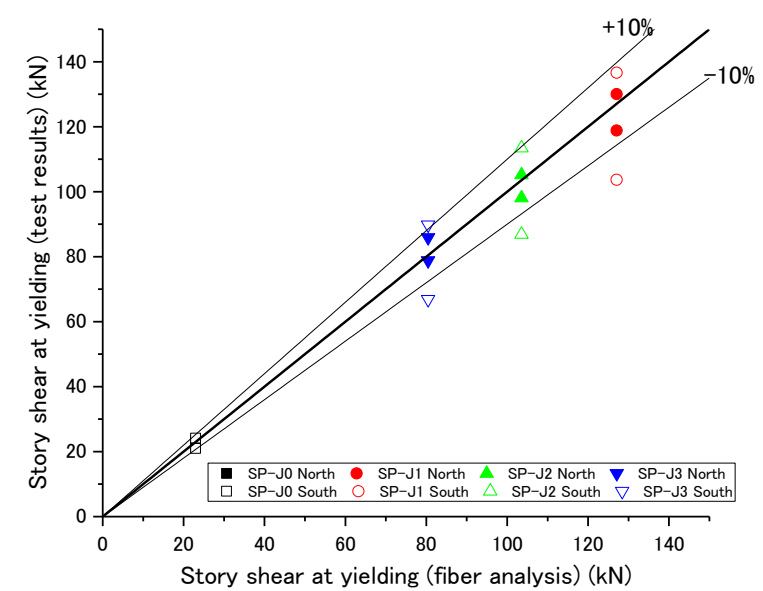

Figure 14: Shear force at the yielding (Experimental result and calculated value).

\section{Modelling of the Beam with Hanging and Standing Walls}

The accuracy of the modelling for non-linear behavior of the beam with hanging and standing walls [8] was confirmed with the test results. A tri-linear model was applied for the behavior as shown in Figure 15, where the initial stiffness, $\mathrm{K}_{0}$, cracking shear strength, $\mathrm{Q}_{\mathrm{cr}}$, stiffness degrading factor at yielding, $\alpha_{y}$, ultimate flexural strength, $\mathrm{Qu}$, and ultimate deflection angle, $\delta_{u}$,

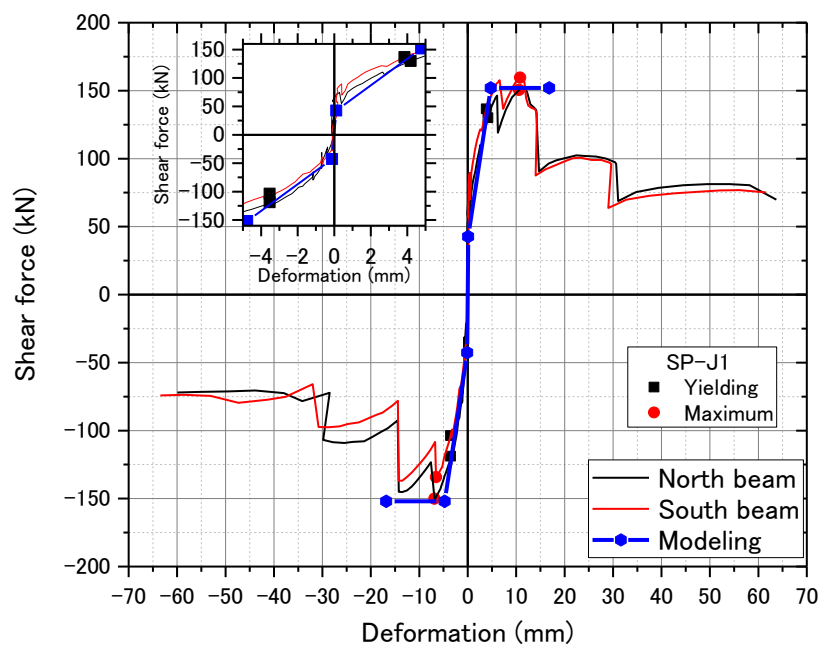

(a) SP-J1 were evaluated with Equations (3), (4), (5), and Equation (6), respectively. The evaluation results are shown in Figure 16. The calculated tri-linear model agreed acceptably well with the test results. The residual restoring force after the peak strength was, however, not able to be evaluated, since no applicable function has been proposed. Development of a new evaluation function for the residual restoring force is needed to consider the postpeak behavior of the beams.

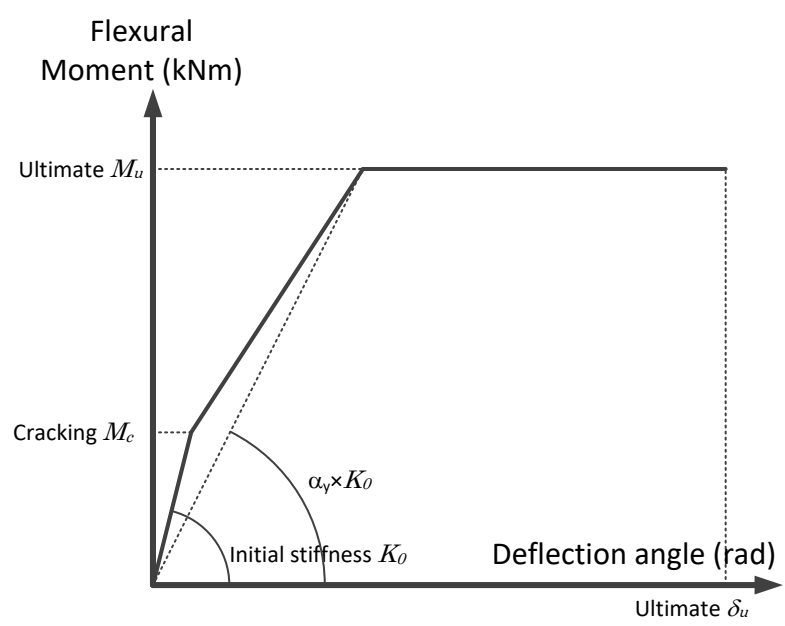

Figure 15: Tri-linear modelling.

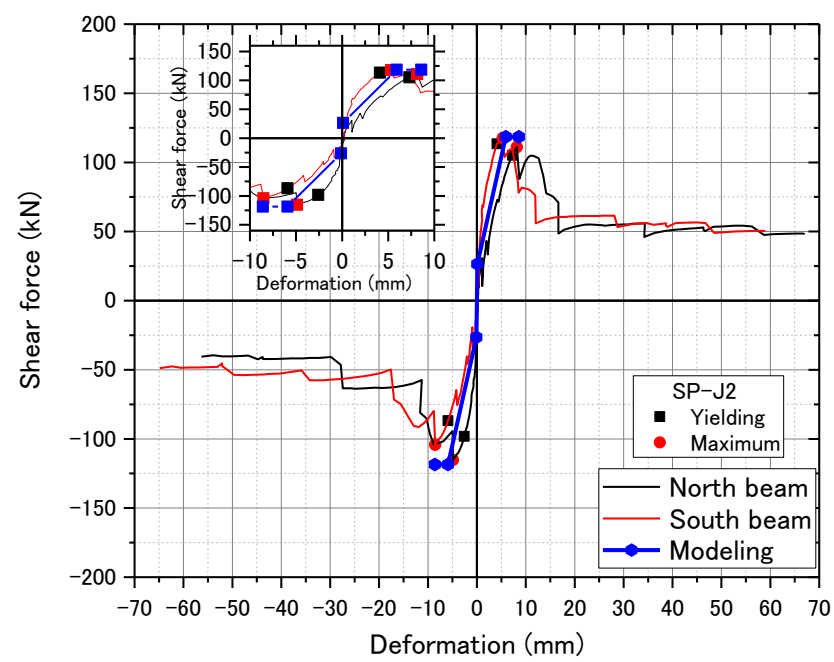

(b) $S P-J 2$

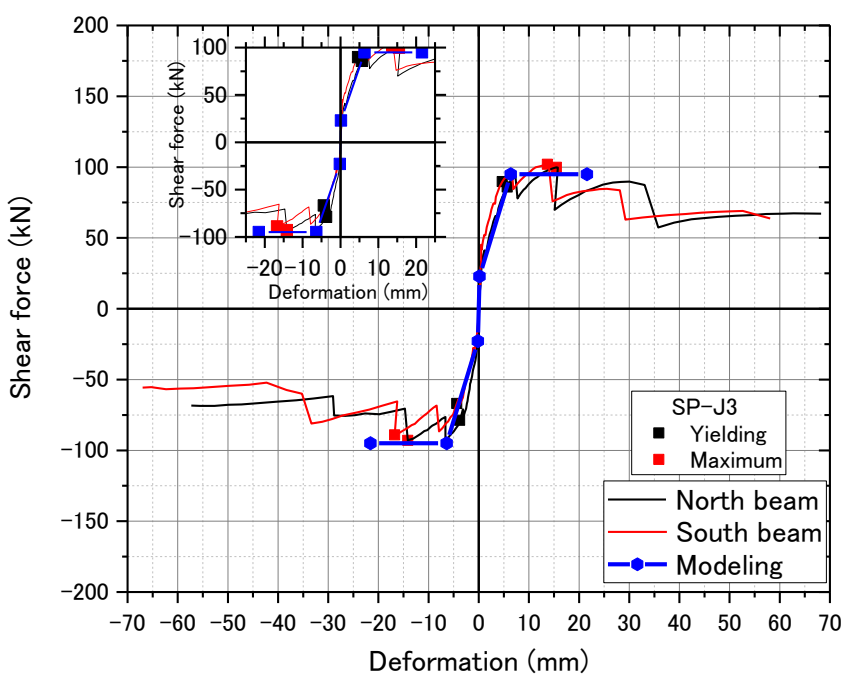

(c) $\mathrm{SP}-\mathrm{J3}$

Figure 16: Comparison between the measured back-bone curve and derived tri-linear model. 
The initial stiffness, $K_{0}$, is calculated with Equation (3).

$\frac{1}{K_{0}}=\frac{1}{K_{s}}+\frac{1}{K_{b e}}$

where, $K_{0}$ : Initial stiffness $(\mathrm{N} / \mathrm{mm})$

$$
\begin{aligned}
& K_{s}=\frac{G_{c} A_{0}}{\kappa_{e} l^{\prime}} \text { Shear stiffness } \\
& K_{b e}=\frac{3 E_{c} I_{e}}{l^{\prime 3}} \text { Flexural stiffness }
\end{aligned}
$$

$\kappa_{e}$ : Shear shape factor calculated as

$\kappa_{e}=\frac{6(2 \alpha \beta+1)\left\{30 \alpha^{2} \beta^{2}(\beta+1)^{2}+2 \alpha \beta\left(16 \beta^{4}+25 \beta^{3}+10 \beta^{2}+5 \beta+5\right)+1\right\}}{5\left(8 \alpha \beta^{3}+12 \alpha \beta^{2}+6 \alpha \beta+1\right)^{2}}$

where, $\alpha=\mathrm{t} / \mathrm{b}$ and $\beta=\mathrm{h} / \mathrm{D}, h$ : is the height of the wall and $D$ is the beam depth.

The cracking flexural strength, $M_{c}$, is calculated as

$M_{c}=0.56 \sqrt{f_{c}} \cdot Z_{e}$

The ultimate flexural strength, $M_{u}$ is calculated with the equilibrium of the section as shown in Figure 17.

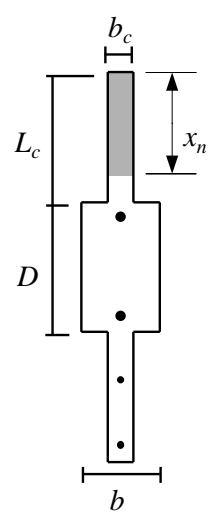

(a) Neutral axis in the wall

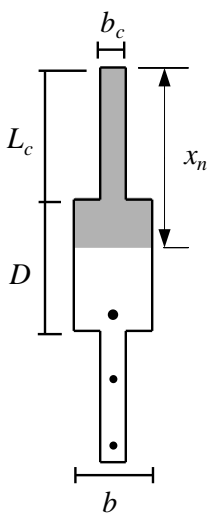

(b) Neutral axis in the beam
Figure 17: Ultimate flexural strength.

The stiffness degrading factor, $\alpha_{y}$, is calculated as

$\alpha_{y}=\left(0.043+1.65 \sum n p_{t}+0.043 \frac{M}{Q L}+0.33 \eta_{0}\right)\left\{\frac{d}{L}\right\}^{2}$

$n$ : Young's modulus ratio (steel bar / concrete)

$p_{t}:$ Ratio of tensile steel bars

$x_{n}=\frac{2}{5}\left(L-y_{\max }\right):$ Neutral axis depth $(\mathrm{mm})$

$M /(Q L):$ Shear span ratio

$\eta_{0}:$ Axial force ratio $(=0)$

$d$ : Effective depth (mm)

$$
d=\frac{\sum a_{t i}\left(d_{i}-x_{n}\right)^{2}}{\sum a_{t i}\left(d_{i}-x_{n}\right)}+x_{n} \quad(\text { see Figure 18) }
$$
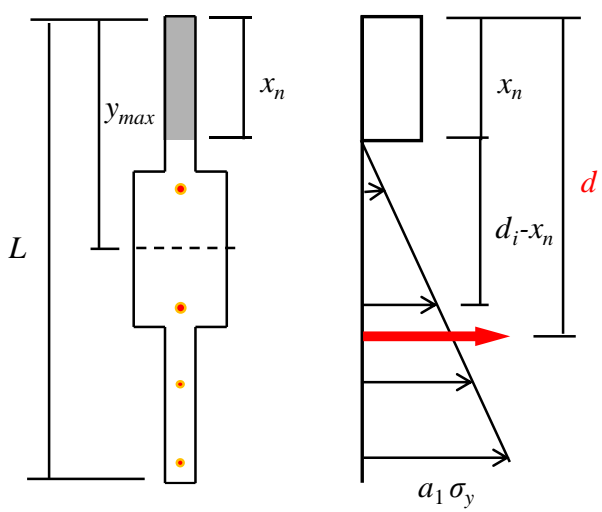

Figure 18: Definition of effective depth d.

The ultimate deflection angle, $R$, is calculated with Equation (6).

$R_{u}=c \times l_{h} \times \phi_{u}$

where, $c$ : Magnification factor $\quad(c=6)$

$l_{h}:$ Length of yield hinge region

$l_{h}=2 t_{w}$ where $t_{w}$ is the thickness of the wall

$\varphi_{u}:$ Curvature in the yield hinge region

$$
\phi_{u}=\frac{\varepsilon_{c u}}{x_{n}}
$$

$\varepsilon_{c u}$ : Compressive strain at the edge of the section $\left(\varepsilon_{c u}\right.$ $=0.003)$

$x_{n}$ : Distance to the neutral axis from the compressive edge (Derived from the sectional analysis)

\section{CONCLUSIONS}

In order to investigate the effect of hanging and standing walls on the effective length of beams (rigid length in the beamcolumn joint) and yield hinge location, a series of static loading tests were conducted. Findings from the tests are as follows:

(1) The restoring force dropped after the maximum point but showed stable behavior with residual strength greater than that for the case without walls.

(2) It is confirmed based on the observed damage, measurement of beam lateral displacement, strain gage data on longitudinal beam bars, and comparisons of computed and measured beam demands at yielding that the beams yielded at the face of the wing wall.

(3) The rigid length in the beam-column joint to evaluate the deformation of the beam was longer than the conventional assumption, which is $\mathrm{D} / 4$ inside the face of the wing wall (D is total depth of the beam).

(4) The tri-linear model of the beam with the standing and hanging walls agreed well with the test results.

More tests with different parameters, such as column/beam flexural strength ratio, are needed generalize the evaluation method such as rigid zone length, modelling and ductility.

\section{ACKNOWLEDGEMENT}

This research was funded as part of national research projects for the consolidation of the Building Standard Law of Japan. 


\section{REFERENCES}

1 Building Center of Japan (2013). "The Building Standard Law of Japan". BCJ, Tokyo.

2 Building Center of Japan (2013). "Article 78-2" in "The Building Standard Law of Japan”. BCJ, Tokyo.

3 The Architectural Institute of Japan (2012). "Damage to Reinforced Concrete Buildings" in "Preliminary Reconnaissance Report of the 2011 Tohoku-Chiho Taiheiyo-Oki Earthquake". AIJ, Tokyo, 47pp.

4 Kabeyasawa T, Kim S, Sato M, Hyunseong H, Kabeyasawa $\mathrm{T}$ and Fukuyama H (2012). "Evaluation on deformability of reinforced concrete columns with wing walls". Proceedings of the 15th World Conference on Earthquake Engineering (15WCEE), Lisbon, Portugal.

5 Tasai A, Sugimoto K, Kusunoki K and Sauod M (2016). "An experimental study on the seismic performance of RC beams with non-structural walls". Journal of Structural Engineering, 62B: 203-212
6 The Architectural Institute of Japan (2011). "AIJ Standard for Structural Calculation of Reinforced Concrete Structures". AIJ, Tokyo (in Japanese).

7 Tasai A, Watanabe H, Kusunoki K, Suzuki A, Fukuyama H and Tajiri S (2009). "An experimental study on performance of RC beams with spandrel walls: Part 2: Studies on deformation capacity and flexural strength of RC beams with spandrel walls". Proceedings of Annual Meeting of the Architecture Institute of Japan, 23035 (in Japanese)

8 National Institute for Land and Infrastructure, and Building Research Institute (2011). "Commentary on Structural Regulations in the Building Standard Law of Japan". Tokyo.

9 Blogg JD, Churchill WT and Shah HP (1995). "Prediction of Catastrophes in New Zealand". Bulletin of the New Zealand Society for Earthquake Engineering, 28(3): 196217. 